\title{
Therapeutic potential of bleomycin plus suicide or interferon- $\beta$ gene transfer combination for spontaneous feline and canine melanoma
}

\author{
Lucrecia Agnetti ${ }^{1}$, Chiara Fondello ${ }^{1}$, Marcela S. Villaverde ${ }^{1}$, Gerardo C. Glikin ${ }^{1}$ and \\ Liliana M. E. Finocchiaro ${ }^{1}$ \\ ${ }^{1}$ Unidad de Transferencia Genética Instituto de Oncología "Ángel H. Roffo" Universidad de Buenos Aires, Buenos Aires, \\ Argentina
}

Correspondence to: Liliana M. E. Finocchiaro, email:finolili@hotmail.com

Keywords: melanoma, HSV-thymidine kinase, interferon- $\beta$, bleomycin, spheroids

Received: July 11,2017 Accepted: November 26, $2017 \quad$ Published:December 28, 2017

Copyright: Agnetti et al. This is an open-access article distributed under the terms of the Creative Commons Attribution License 3.0 (CC BY 3.0), which permits unrestricted use, distribution, and reproduction in any medium, provided the original author and source are credited.

\section{ABSTRACT}

We originated and characterized melanoma cell lines derived from tumors of two feline and two canine veterinary patients. These lines reestablished the morphology, physiology and cell heterogeneity of their respective parental tumors. We evaluated the cytotoxicity of bleomycin (BLM) alone, or combined with interferon- $\beta$ (IFN- $\beta$ ) or HSVtk/GCV suicide gene (SG) lipofection on these cells. Although the four animals presented stage III disease (WHO system), SG treated feline tumors displayed stable disease in vivo, while the canine ones exhibited partial response. Their derived cell lines reflected this behavior. Feline were significantly more sensitive than canine cells to IFN- $\beta$ gene transfer. BLM improved the antitumor effects of both genes. The higher levels of reactive oxygen species (ROS) significantly correlated with membrane and DNA damages, emphasizing ROS intervention in apoptotic and necrotic cell death. After 3 days of BLM alone or combined with gene treatments, the colony forming capacity of two canine and one feline treatments survivor cells almost disappeared. Taken together, these results suggest that the treatments eradicated tumor initiating cells and support the clinical potential of the tested combinations.

\section{INTRODUCTION}

Some types of human cancer are very similar to the corresponding disease in companion animals. The auspicious results, derived from immunogene therapy studies carried out in companion animals, warrant their usage in veterinary clinical oncology $[1,2]$. Progress made with veterinary cancer bearing patients can significantly speed up translational research and benefit both veterinary and human patients.

Malignant melanoma (MM) is rare in cats while is one of the most common tumors in dogs [1-6]. Being clinically similar, both diseases are chemo and radioresistant and share similar phenotypes [3-6]. Locally growing at first, feline and canine MM eventually will invade the lymph nodes and spread to other areas of the body. The internal organs most commonly affected are the lungs, but it can spread to any part of the body [3-6]. These extremely aggressive spontaneous tumors, frequently resistant to current therapies, urgently need new therapeutic strategies.

Intratumor non-viral suicide gene (SG) therapy with thymidine kinase from the herpes simplex virus (HSVtk), in combination with the pro-drug ganciclovir (GCV), has been extensively and successfully used for treating canine malignant diseases $[1,2,5,6]$. On the other hand, Interferon- $\beta$ (IFN $\beta$ ) has antitumor effects against melanoma, and generally is more potent than IFN $\alpha[6$, 7]. Even though clinically effective, the treatment with recombinant hIFN $\alpha / \beta$ protein is associated with substantial systemic toxicity that worsens the patient's quality of life and often interferes with the therapy completion 
Table 1: Characteristics of cultured melanoma cells

\begin{tabular}{|l|l|l|l|l|}
\hline Cell line & $\boldsymbol{D} \boldsymbol{l}$ & $\boldsymbol{R} \boldsymbol{R}$ & $\boldsymbol{B s} \boldsymbol{R}$ \\
\hline Origin & oral & abdominal & oral & oral \\
\hline Cell morphology & epithelioid & fibroblastic & fibroblastic & fibroblastic \\
\hline Spheroid morphology & loose (multiple) & compact & loose & loose \\
\hline Lipofection rate (\%) [n] & $3.01 \pm 1.61[8]$ & $1.80 \pm 0.71[12]$ & $26.54 \pm 7.23[15]^{* *}$ & $16.81 \pm 6.91[12]^{*}$ \\
\hline Duplication time (h) [n] & $18.08 \pm 1.90[3]$ & $19.89 \pm 2.49[4]$ & $28.87 \pm 2.36[4]^{*}$ & $29.93 \pm 1.09[3]^{*}$ \\
\hline Proliferation Index (\%) [n] & $41.18 \pm 1.03[4]$ & $47.35 \pm 2.00[4]$ & $48.07 \pm 4.19[3]$ & $39.12 \pm 5.28[6]$ \\
\hline ROS (geometric mean) [n] & $21.47 \pm 4.02[4]$ & $15.41 \pm 2.00[4]$ & $36.73 \pm 3.50[4]^{* *}$ & $51.26 \pm 2.98[3]^{* * *}$ \\
\hline Cell granularity (mean) [n] & $999.85 \pm 86.06[7]^{* * *}$ & $1720.73 \pm 109.18[6]$ & $913.07 \pm 158.93[7]^{* *}$ & $996.06 \pm 55.70[6]^{*}$ \\
\hline Cell size (mean) [n] & $2024.80 \pm 204.89[3]^{*}$ & $1564.45 \pm 141.43[3]$ & $1875.11 \pm 138.17[3]^{*}$ & $1941.58 \pm 116.77[3]^{*}$ \\
\hline $\begin{array}{l}\text { Clonogenic capacity } \\
\text { (\% seeded cells) [n] }\end{array}$ & $9.14 \pm 2.35[7]^{* * *}$ & $33.11 \pm 1.66[3]$ & $11.68 \pm 1.95[6]^{* * *}$ & $3.90 \pm 0.50[3]^{* * *}$ \\
\hline $\begin{array}{l}\text { Colonies in soft agar } \\
\text { (\% seeded cells) [n] }\end{array}$ & $13.08 \pm 1.17^{* *}$ & $22.83 \pm 1.86$ & $9.16 \pm 1.03^{* * *}$ & $5.37 \pm 0.53^{* * *}$ \\
\hline $\begin{array}{l}\text { Melanosphere forming } \\
\text { capacity (\%) }\end{array}$ & n.d. & $11.18 \pm 5.53[3]$ & $6.715 \pm 0.12[2]$ & n.d. \\
\hline
\end{tabular}

Time course of growth was determined by trypan blue exclusion cell counting and lipofection efficiency was measured as blue X-Gal stained cells as described in Materials and methods. Proliferation index (PIx) of untreated cells was determined by evaluating the percentage of cells in the S, G2/M and hyperdiploid phases. ROS: Reactive oxygen species. n.d.: not determined. * vs Rn respective value. One symbol: $\mathrm{p}<0.05$, two symbols: $\mathrm{p}<0.01$, three symbols: $\mathrm{p}<0.001$.

[8]. However, the exogenously added recombinant IFN $\beta$ protein (rIFN $\beta$ ) can be successfully replaced by the transfer of the corresponding gene in vitro [7]. Local non-viral delivery of the gene encoding this cytokine provides a slow release transgenic system limited to a small area, avoiding the adverse events associated to the injection of high doses of recombinant interferon protein while keeping its therapeutic potential [6]. In addition, lipoplexes can facilitate the delivery of bleomycin (BLM) into melanoma cells via endocytosis [9]. This antineoplastic agent enhances the cytotoxic effects of both SG and IFN $\beta$ gene expression on human melanoma and sarcoma cells [10].

Generally, these studies use established tumor cell lines that were kept in culture for many generations, making them very different from the original tumors. Conversely, companion animals' primary melanoma cell lines, could offer alternative promising models for optimizing and predicting the in vivo response of their respective tumors to therapeutic strategies [11]. Besides, few stable feline and canine melanoma cell lines are currently available. Thus, we established and characterized four melanoma cell lines derived from surgically excised canine and feline melanoma tumors. On these lines, we explored the therapeutic potential of the combination of
BLM with IFN $\beta$ gene and SG lipofection.

\section{RESULTS}

\section{Melanoma cell lines were derived from highly malignant in vivo tumors}

To evaluate potential in vivo responses of individual spontaneous feline and canine melanomas to our treatments, we established and characterized four melanoma cell lines, two feline $(D c$ and $R n)$ and two canine (Bsk and $R k$ ). They derived from surgically excised feline oral $(D c)$ and abdominal $(R n)$ and canine oral mucosal melanoma ( $B s k$ and $R k$ ) advanced tumors of veterinary patients.

Dc feline patient was bearing a highly malignant gingival mass of $3.1 \mathrm{~cm}$ mean diameter expanding to the ipsilateral lymph node (mean diameter $2.2 \mathrm{~cm}$ ).

Rn feline patient: was carrying two large lesions (mean diameter: $7.2 \mathrm{~cm}$ and $5.9 \mathrm{~cm}$ respectively) of an abdominal highly advanced melanoma with metastatic spread all over the abdomen.

Bsk canine patient: was bearing a recurrent oral 
tumor progressing on the right maxilla of $3.3 \mathrm{~cm}$ mean diameter spread to the ipsilateral lymph node (mean diameter $5.7 \mathrm{~cm})$.

Rk canine patient: was bearing a primary melanoma on the left maxilla of $4.7 \mathrm{~cm}$ mean diameter with an osteolytic metastatic spread.

\section{Melanoma cell lines displayed considerable heterogeneity}

Melanoma cell lines derived from feline and canine tumors of our veterinary patients seem to be able to reestablish the morphologic and physiologic phenotype of their respective in vivo tumors. Compatible with the clinical diversity of this disease, feline and canine melanoma cells displayed high heterogeneity related to the high variability of cell populations $[5,6,12,13]$.

Feline cell lines $(D c, R n)$ displaying significantly

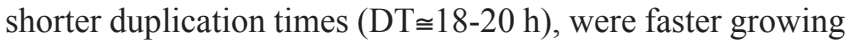
than the canine ones $(B s k, R k)$ with $\mathrm{DT} \cong 28-30 \mathrm{~h}$. However, the four cell lines exhibited similar proliferation index (PIx) as the proportion of cells in $\mathrm{S}, \mathrm{G}_{2} / \mathrm{M}$ and hyperdiploid phases (Table 1).

In agreement with the highly malignant and invasive $\mathrm{Rn}$ tumor, $R n$ derived cell line also displayed a more aggressive phenotype by forming respectively 2-, 2- and 4-fold more colonies in soft agar; and 3-, 3- and 7- fold more adherent colonies than $D c$, Bsk and $R k$. Accordingly,
$R n$ cell line displayed the greatest proportion of cells with lower basal ROS levels, lower size and higher complexity (Table 1). All these characteristics have been associated with a pluripotent/stem cell phenotype [14-18].

\section{Feline and canine melanoma cells were able to form colonies and melanospheres}

The four melanoma cell lines, when seeded at low density, were able to grow as colonies, either in suspension (soft agar) or under adherent conditions.

Under non-adherent conditions, the four cell lines formed colonies of different morphology when seeded at the same concentration. $D c$ produced the biggest spherical colonies, while $R n, B s k$ and $R k$ tended to form small irregular aggregates (Fig.1).

On the other hand, the shape of the colonies formed under adherent conditions was very different from those in soft agar. Dc, Bsk and $R k$ tended to form spherical aggregates of looser structure. $R k$ ones adopted a smaller and lax structure. Consistent with the high heterogeneity of cell populations, $R n$ tended to form both elongated aggregates and dense spherical colonies displaying a spreading pattern. After reaching a definite size, $R n$ colonies spontaneously became dense spherical masses that easily detached and persisted at the supernatant of the well plate (Fig.1).

Moreover, feline $R n$ and canine Bsk melanoma cells were able to form round and compact melanospheres when

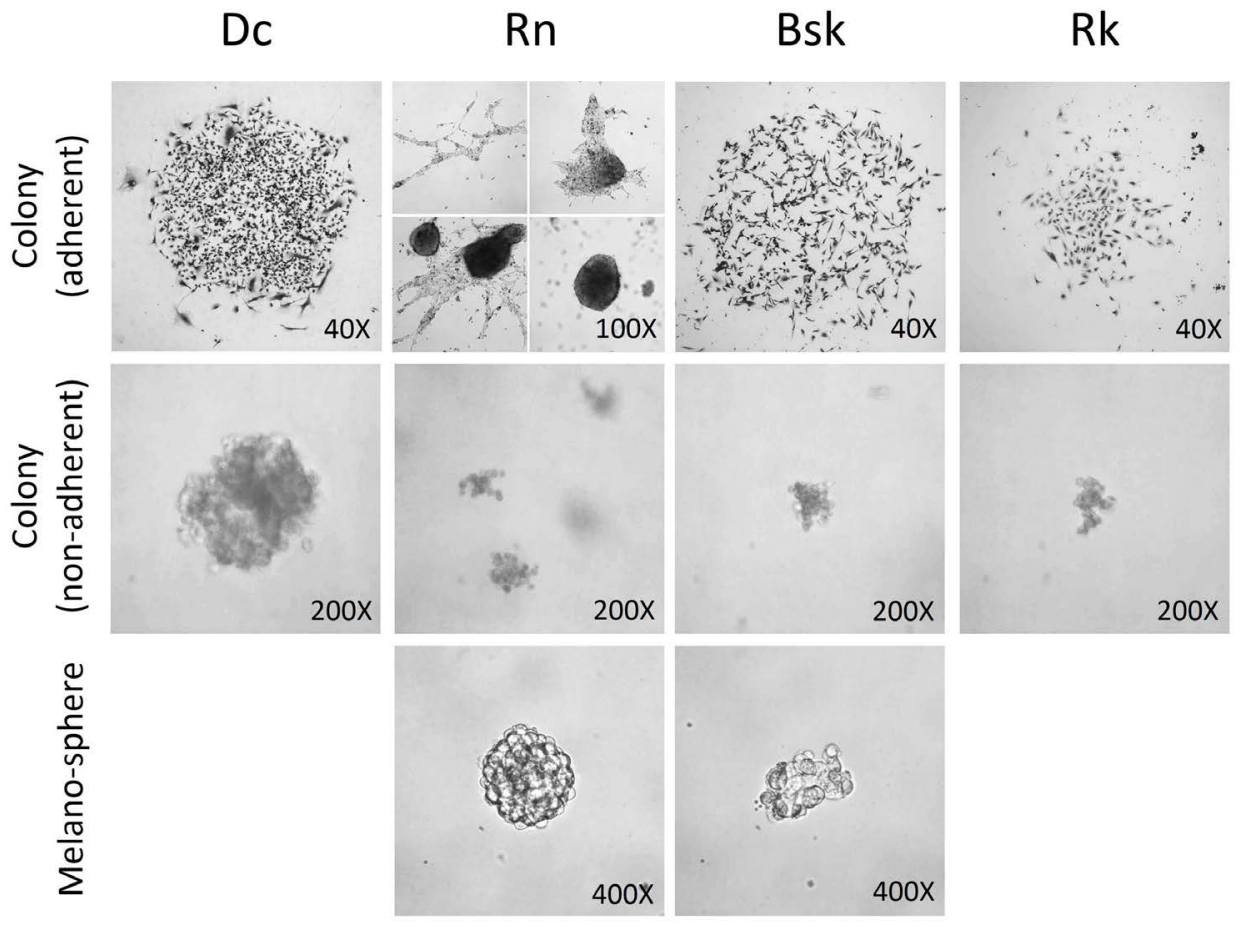

Figure 1: Colonies morphology under adherent and non-adherent (in soft agar) conditions and melanosphere morphology. Colonies and melanospheres growing under adherent or non adherent conditions, as described in Materials and Methods, were photographed using a Nikon eclipse TE2000-S inverted phase contrast microscope. 
seeded under non-adherent and serum-free conditions (Fig. 1).

\section{Specific markers evidenced the invasive and proliferative status of feline and canine melanoma cells}

Consistent with its faster growing, $D c$ and $R n$ nuclei were highly positive for the specific proliferation marker Ki67 (Fig. 2). The expression of this a nuclear antigen, indicator of proliferating cells [19], was moderate in Bsk and low in $R k$.

In addition, Melan A and gp100, two specific and sensitive melanoma antigens associated with cell proliferation programs [20], were very elevated in $R n$ cell line. Melan A (expressed in pigmented cells) was also high in $D c$, moderate in $R k$ and low in Bsk. Gp100 (expressed in activated melanocytes) was high in $R k$, moderate in Bsk and low in $D c$.
In agreement with its fibroblastic phenotypes (Table 1), Rn, Bk and Rk melanoma cell lines, were positive for the mesenchymal marker vimentin (Fig. 2). Even $D c$, displaying a more epithelioid morphology showed a vast subpopulation of vimentin expressing cells. It is worth to note that, the four vimentin positive cell lines, also co-expressed cytokeratin (CK, a keratinocyte specific marker), confirming their invasive and metastatic behavior [21].

On the other hand, S100A9, a member of S100 family, was high in $R n$, moderate in $R k$ and low in $D c$ and $B s k$ (Fig. 2). S100A9 (myeloid-related protein 14), implicated in the abnormal differentiation of myeloid cells in the cancer stroma, contributes to create an immunosuppressive microenvironment that inhibits the generation of a protective cellular immune response by the tumor-bearing host [22]. Furthermore, only $R n$ expressed the lysosome-associated glycoprotein CD68 (data not shown).

Beyond depicting their proliferative and invasive

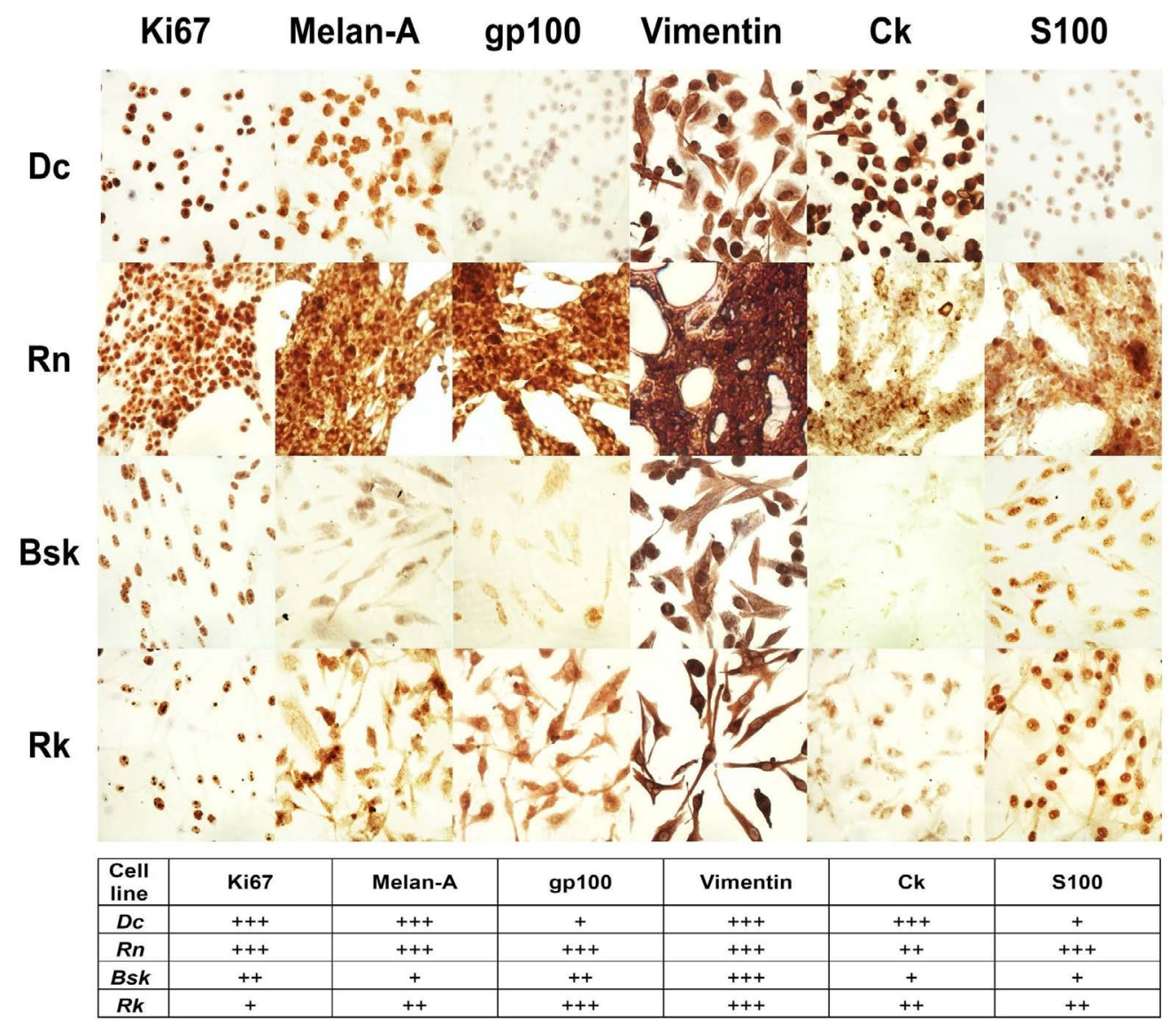

Figure 2: Detection of melanoma specific antigenic markers by immunocitochemistry. Cells growing for 2 days onto glass slides were fixed and stained with specific antibodies against ki67, melan-A, gp100, vimentin, cyitokeratin (Ck) and S100A9 as described in Materials and methods and photographed (400X). The number of + symbols represents a semi-quantitative estimation of the relative staining of each individual tumor marker among the four cell lines. 
status, the morphologic analysis and the positive staining for most of the assayed markers confirmed the previous histopathological diagnosis of melanoma.

\section{Bleomycin enhanced the cytotoxic effects of both suicide and IFN $\beta$ gene lipofection on melanoma cells growing as monolayers and spheroids}

The development of new combinations of treatment strategies could extensively target different cancer cell subpopulations overcoming treatment resistance. In a previous work, we found that, the in vitro response of tumor derived spheroids (sph) correlated with the clinical outcome of the suicide gene treatment observed on canine melanoma patients in vivo [11]. Here, we explored if both, species-specific feline/canine interferon- $\beta$ (f/cIFN $\beta$ ) gene and herpes simplex thymidine kinase/ganciclovir (HSVtk/ GCV) suicide gene (SG) therapy could be successfully combined with bleomycin (BLM) for treating melanoma derived cell lines growing as monolayers (mnl) or sph. We estimated the BLM effect at $3 \mu \mathrm{g} / \mathrm{ml}$ and SG cytotoxicity at the pharmacologically relevant $5 \mu \mathrm{g} / \mathrm{ml}$ ganciclovir (GCV) concentration, similar to the intratumor standard dose for our feline and canine patients [5-7].

With the exception of $\mathrm{SG}$ in $R n$ growing as sph, the tested cell lines were sensitive to both, IFN $\beta$ and SG lipofection in both spatial configurations (Fig. 3). Canine cell lines $(B s k, R k)$, with higher lipofection efficiency

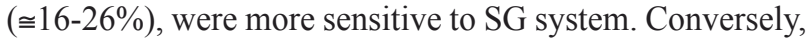
feline cell lines $(D c, R n)$, presenting very low lipofection efficiency ( $\cong 2-3 \%$ ), were more sensitive to IFN $\beta$ gene in both spatial configurations (Table 1, Fig. 3). Surprisingly, Rn cell line with fair lipofection efficiency ( $\cong 2 \%)$ was sensitive, not only to fIFN $\beta$ in both spatial configurations, but also to SG gene when growing as mnl.

All cell lines were sensitive to BLM alone: $D c$ and $R k$ (mnl and sph), Bsk (mnl) and Rn (sph). However, unspecific lipofection ( $\beta$ gal) enhanced BLM cytotoxicity in the four lines: $D c, B s k$ and $R k(\mathrm{mnl})$, and $R n$ (sph). This effect was probably due to lipoplexes-mediated cellular uptake [9]. On the other hand, the combination with BLM enhanced the individual effects of both, fIFN $\beta$ and SG gene, in feline lines ( $D c$ and $R n)$, and the cIFN $\beta$ effects in canine lines (Bsk, $\mathrm{mnl}$ and $\mathrm{sph}$; and $R k, \mathrm{mnl})$. The highly sensitive canine cell lines, showed equal $(\mathrm{mnl})$ or greater response (sph) to the combination BLM/SG with respect to SG alone (Fig. 3).

$R k$ showed greater response to both, $\mathrm{SG}$ and cIFN $\beta$ gene, as monolayers than as their respective spheroids and $R n$ did so only in response to SG (Fig. 3). This decreased sensitivity of spheroids would be due to the phenomenon called multicellular resistance (MCR) that reflects the relative intrinsic treatment-resistant phenotype of most solid tumors growing in vivo [11].

As observed in Fig. 3b, the microscopic monitoring of treated spheroids paralleled the results obtained in the bar plots.

In agreement with the high heterogeneity of melanoma, the four cell lines were able to grow as multicellular spheroids of different morphologies. The small size and looser structure of $D c$ sph, became more lax after treatments (SG excepted). Conversely, $R n$ cells appeared intimately associated with each other and closely packed. Treatments, specially the combined ones, resulted in a significant reduction of spheroids volume, while maintained their degree of compactness (Fig. 3b).

On the other hand, Bsk tended to form spherical aggregates displaying a spread pattern, while $R k$ formed intermediate cell clusters. In both canine cell lines, cIFN $\beta$ gene lipofection alone and combined with BLM caused a morphological change consistent of multiple small aggregates of cells loosely associated with each other. The rest of the treatments decreased the spheroid size while maintained their morphology.

\section{In vitro suicide gene sensitivity correlated with in vivo tumor response of feline and canine melanoma patients}

Although the four patients presented stage III disease (tumor $>4 \mathrm{~cm}$ and/or positive nodes), as defined by WHO staging system, the variability of responses between individual patients to SG treatment, was compatible with the clinical diversity of this disease.

During our veterinary clinical study, Bsk and Rk patients displayed a partial response to SG [5], while Dc presented stable disease during the 5 weekly suicide gene treatments [Finocchiaro et al., unpublished data]. On the other hand, the enormous and highly invasive Rn tumor showed a fast progression in situ before gene therapy, with both large lesions doubling their volume in only 3 weeks (from 57.6 to $113.3 \mathrm{~cm}^{3}$ and from 47.2 to $86.7 \mathrm{~cm}^{3}$ ). Tumor growth stopped during the 5 weekly treatments with SG, becoming a stable disease. There was little change in size for the following 10 weeks and after that growth resumed [Finocchiaro et al., unpublished data].

\section{Chemo-gene treatments increased the fraction of

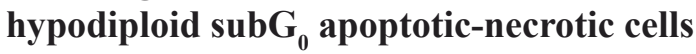

Cells dying by apoptosis, a regulated cell death, activate endonucleases that cleave DNA in fragments of approximately 180-200bp. Conversely, necrotic cell death occurs drastically, leading to plasma membrane permeabilization and to a rapid non-specific cleavage of DNA. Thus, cells undergoing apoptosis/necrosis $(\mathrm{A} / \mathrm{N})$ can be readily identified by flow cytometry as cells with hypodiploid or subG $\mathrm{DNA}_{0}$ content after propidium iodide staining.

The levels of DNA breakup observed in the cells treated with $\beta$ gal lipofection alone were not significantly 
Dc

a)

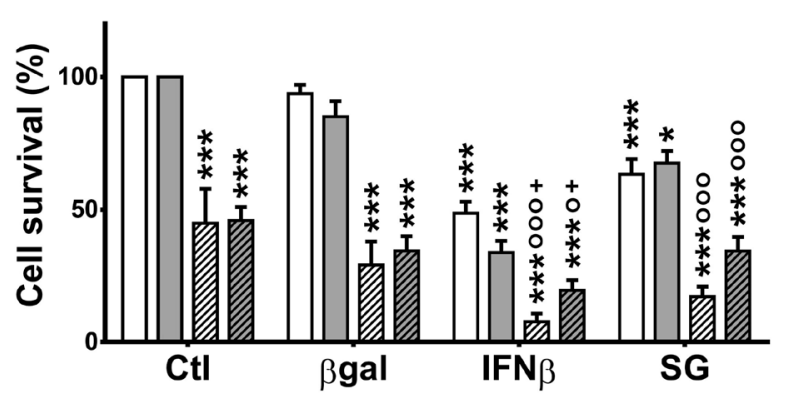

b)

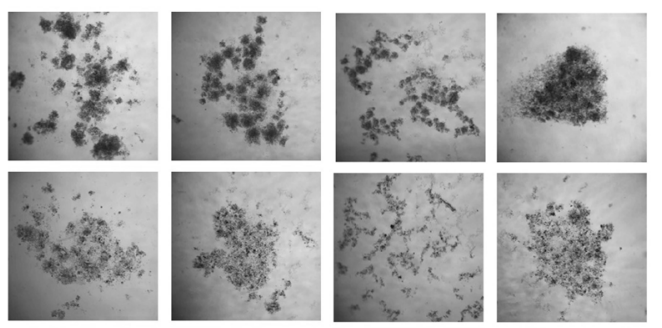

Bsk

c)

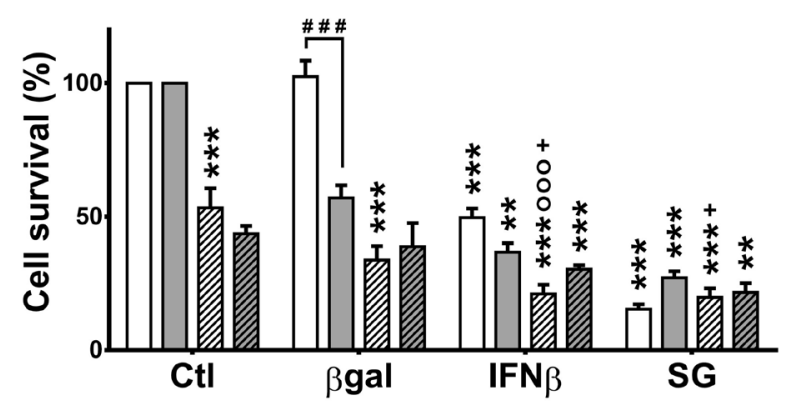

d)
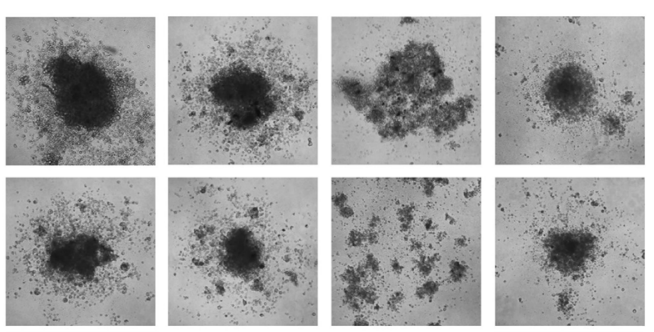

$\mathrm{Rn}$

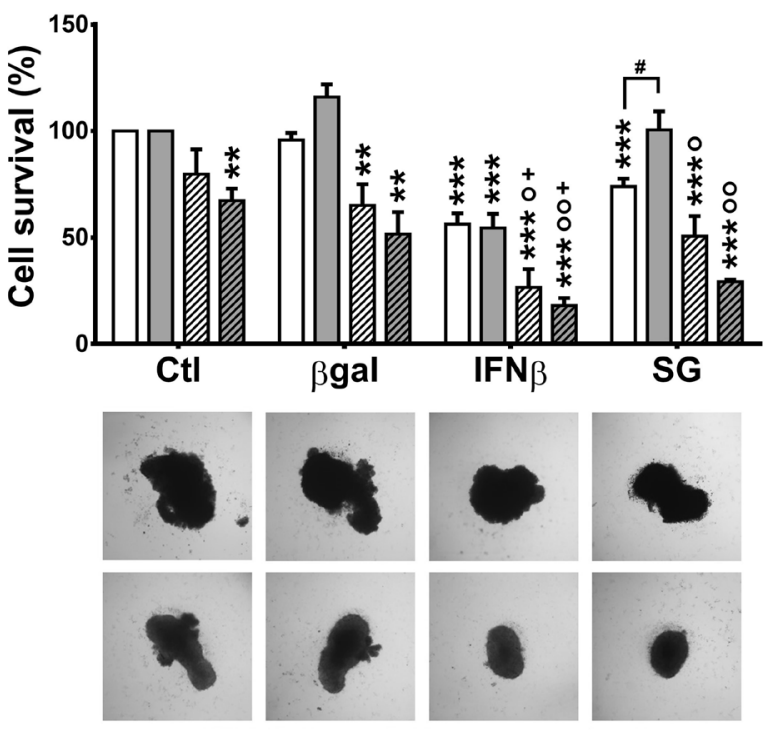

Rk
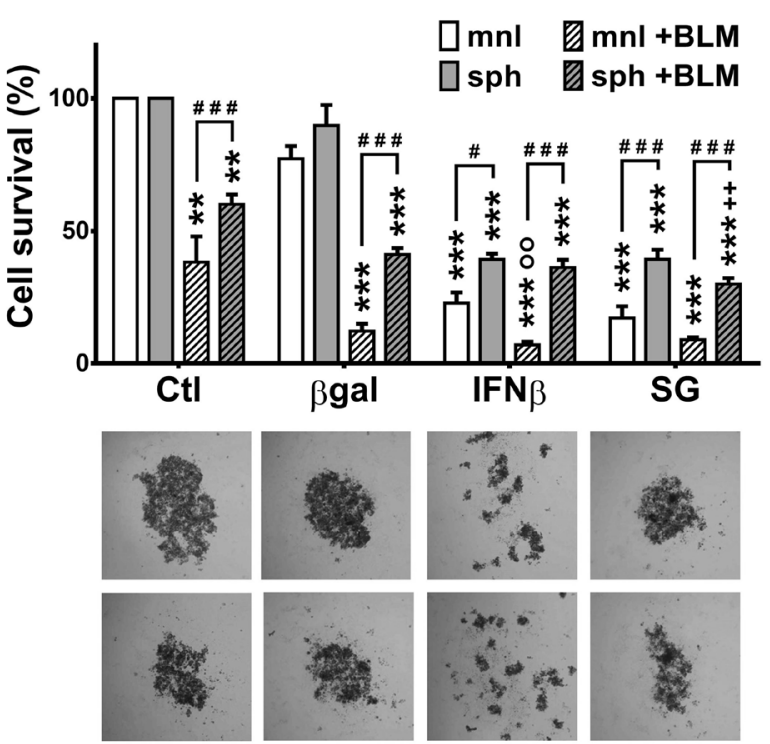

Figure 3: Effect of bleomycin (BLM) on the sensitivity of melanoma cells monolayers and spheroids to interferon- $\beta$ (IFNß) gene and suicide gene (SG) system (HSVtk/GCV) as described in Materials and methods. (a,c) The results represent means \pm s.e.m. of $\mathrm{n} \geq 4$ ( $R n$ and $B s k), \mathrm{n} \geq 6(R k)$ and $\mathrm{n} \geq 8(D c)$ independent experiments. In this case each value was relative to the respective control condition: monolayers (mnl) or spheroids (sph). * vs the respective $\beta g a l ;$ o BLM vs their respective value without $\mathrm{BLM} ;+\mathrm{BLM} /$ genes combined treatments vs their respective ctl+BLM; \# sph vs their respective value in mnl. One symbol: $\mathrm{p}<0.05$, two symbols: $\mathrm{p}<0.01$, three symbols: $\mathrm{p}<0.001$. (b,d) Images represent individual melanoma spheroids treated as described in the bar plots. Spheroids growing in suspension in 96 -well plates for 10 days were photographed using an inverted phase contrast microscope (100X). 
different from those observed in unlipofected control cells. SG produced a significant increase of cells accumulated in the hypodiploid $\mathrm{subG}_{0} \mathrm{~A} / \mathrm{N}$ region in the four cell lines. IFN $\beta$ gene lipofection did so in $D c$ and $R k$. Interestingly, BLM alone or combined with gene treatments, increased even more this fraction of cells in the four cell lines (Fig. 4a).

On the other hand, the four cell lines exhibited an inverse correlation between the fraction of hypodiploid subG $_{0} \mathrm{~A} / \mathrm{N}$ cells and cell survival to all the treatments in both spatial configurations (Fig. 4b).

\section{The treatments increased the fraction of necrotic cells}

In contrast to the apoptotic pathway, necrosis has obvious implications for the in vivo success of treatments. The intracellular content leaking to the extracellular space through damaged plasma membrane may induce the development of in vivo strong immune response that could provide additional antitumor activity. In order to quantify this process, we measured propidium Iodide (PI) uptake by unfixed necrotic cells with permeable plasma membranes.

Three days after IFN $\beta$ gene and SG lipofection the four cell lines significantly increased the necrotic cell death. BLM alone or combined with both genes induced a significant additional increase of necrotic cells (Fig. 5a).

On the other hand, the four cell lines exhibited an inverse correlation between the fraction of necrotic cells and cell survival to all the treatments in both spatial configurations (Fig. 5b).

\section{Chemo-gene treatments increased the subpopulation of cells with high ROS content}

Reactive oxygen species (ROS) play a major role as mediators of IFN $\beta$ gene cytotoxic effects in human and canine melanoma cell lines [7]. Thus, we explored a possible link between the cytotoxicity of BLM- gene treatments and the increase in intracellular ROS in our new established cell lines.

Compared to control cells, we observed that, a subpopulation of cells with high intracellular levels of ROS was significantly increased by IFN $\beta$ gene, in feline $(D c$ and $R n$ ) and canine $(R k)$ melanoma cells. Conversely, a)

Dc

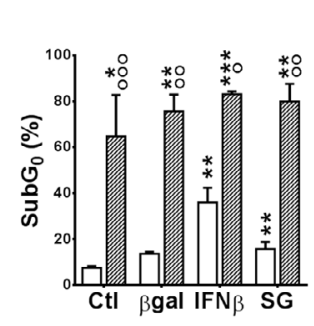

b)
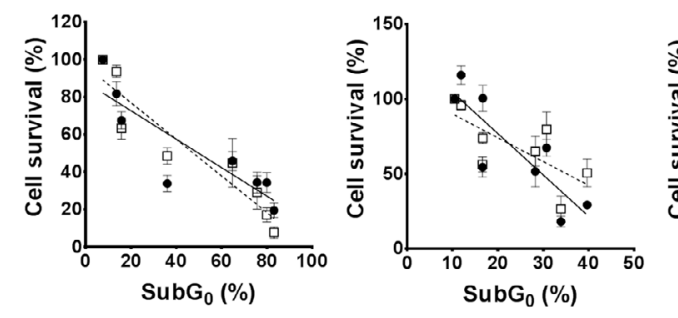

Rn

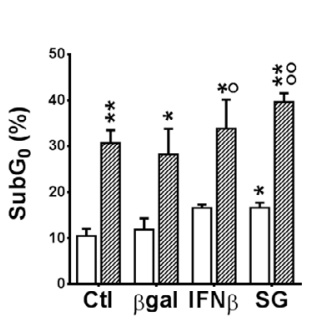

Bsk
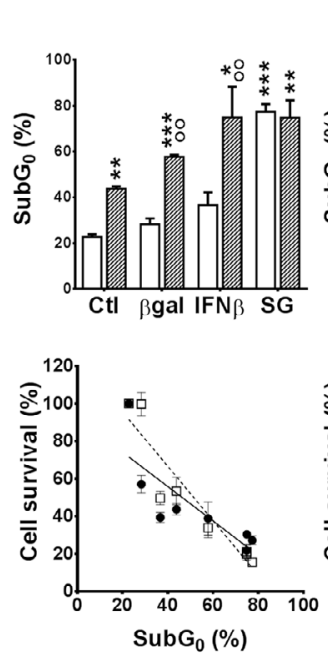

Rk

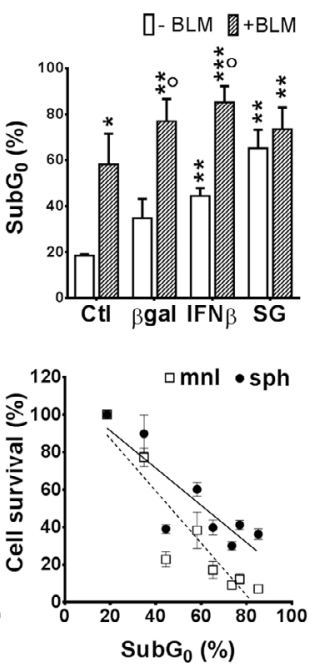

\begin{tabular}{|c|c|c|c|c|c|c|c|c|}
\hline \multirow{2}{*}{ SubG } & \multicolumn{2}{|c|}{$\mathbf{D c}$} & \multicolumn{2}{c|}{$\mathbf{R n}$} & \multicolumn{2}{c|}{ Bsk } & \multicolumn{2}{c|}{$\mathbf{R k}$} \\
\cline { 2 - 10 } & $\mathbf{R}^{\mathbf{2}}$ & $\mathbf{p}<$ & $\mathbf{R}^{\mathbf{2}}$ & $\mathbf{p}<$ & $\mathbf{R}^{\mathbf{2}}$ & $\mathbf{p}<$ & $\mathbf{R}^{\mathbf{2}}$ & $\mathbf{p}^{2}$ \\
\hline mnl & 0.881 & 0.001 & 0.516 & 0.05 & 0.882 & 0.001 & 0.839 & 0.01 \\
\hline sph & 0.769 & 0.01 & 0.730 & 0.01 & 0.669 & 0.05 & 0.735 & 0.01 \\
\hline
\end{tabular}

Figure 4: Effects of IFN $\beta$ gene and SG (HSVtk/GCV) lipofection in the absence or presence of BLM on apoptoticnecrotic cell death of melanoma cells. (a) The fraction of hypodiploid subG $\mathrm{G}_{0}$ apoptotic cells was determined by flow cytometry as described in M\&M. The results represent means \pm s.e.m. of $n \geq 3$ independent experiments. * vs the respective $\beta$-galactosidase gene ( $\beta$ gal); o BLM vs their respective value without BLM; + BLM/genes combined treatments vs their respective ctl+BLM; + BLM/genes combined treatments vs their respective $\beta$ gal+BLM. One symbol: $p<0.05$, two symbols: $p<0.01$, three symbols: $p<0.001$. (b) Correlations between hypodiploid subG0 apoptotic cells and cells survival to all treatments in $\mathrm{mnl}$ (口) or $\operatorname{sph}(\bullet)$ were determined by Pearson test with GraphPad Prism program. 
SG induced a significant ROS increase only in canine cell lines $(B s k, R k)$ (Fig. 6a). It is worth to note the high increase of ROS produced by BLM alone or combined with IFN $\beta$ gene and SG lipofection in the four cell lines. (Fig. 6a).

The rise in ROS levels correlated with the extent of the cytotoxic response. The four cell lines exhibited an inverse correlation $(\mathrm{p}<0.05)$ between intracellular ROS levels and cell survival to the chemo-gene treatments in both spatial configurations (Fig. 6b).

On the other hand, we found a direct correlation between the subpopulation of cells with high intracellular levels of ROS and the fraction of hypodiploid subG $\mathrm{G}_{0} \mathrm{~A} / \mathrm{N}$ cells (Fig.6c), and with the proportion of necrotic cells with PI-positive nuclei (Fig. 6c), in the four cell lines.

\section{The treatments modified the fraction of cycling cells}

In a previous paper we demonstrated that, opposing to the treatment, there is a repopulation (re-growth) mechanism whose strength would be intrinsic of each individual tumor [11].
In canine cell lines, SG and combined treatments increased the proportion of cells with high proliferation index (PIx) (Fig. 7a). Furthermore, both single and combined treatments enhanced the proliferative phenotype of $D c$ cells. Conversely, only SG enhanced the proliferative fraction of $R n$ feline cell line.

On the other hand, $D c, B s k$, and $R k$ cell lines, exhibited an inverse correlation between the fraction of cells with high PIx and the extent of cell survival to treatments in both spatial configurations (Fig. 7b).

\section{Surviving tumor cells displayed a reduced clonogenic capacity after treatments}

Due to the re-growth resistance effect found after an early fast destruction of tumor cells both in vivo and in vitro, the long term outcomes of the treatment often differ from short term cytotoxic effects. Clonogenic survival studies are useful for to evaluate these long term consequences and confirmed that the combination was more effective than the individual treatments (Fig. 8a,b).
Dc

a)

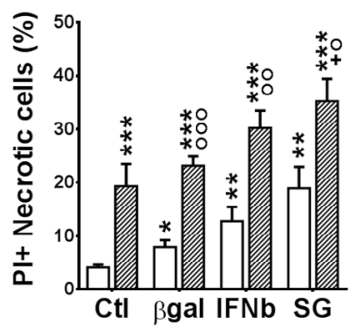

b)

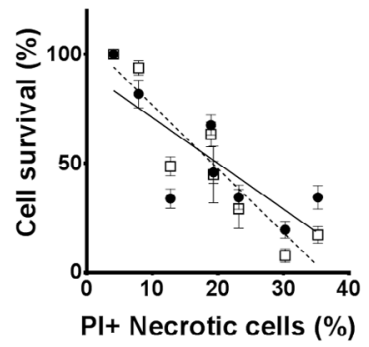

$\mathbf{R n}$
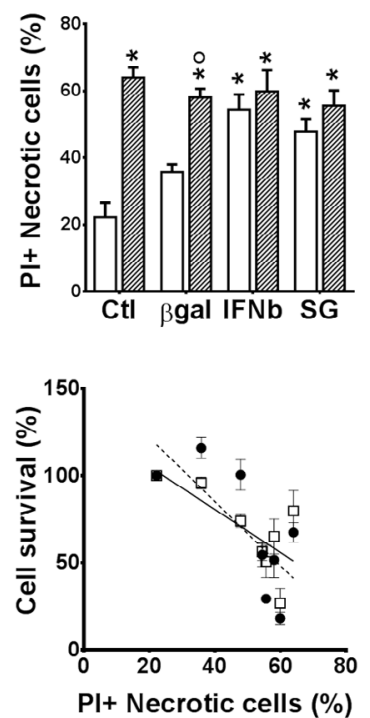

Bsk
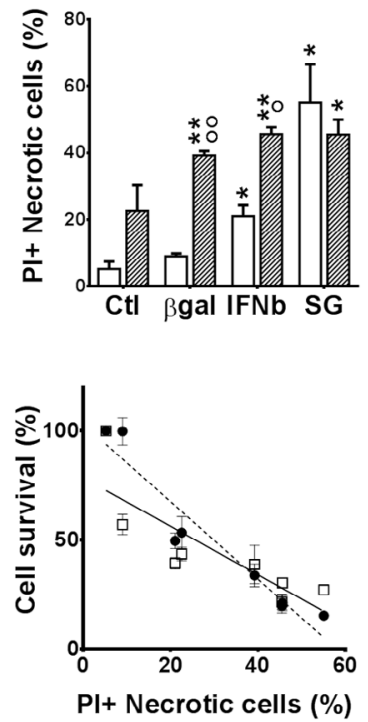

Rk
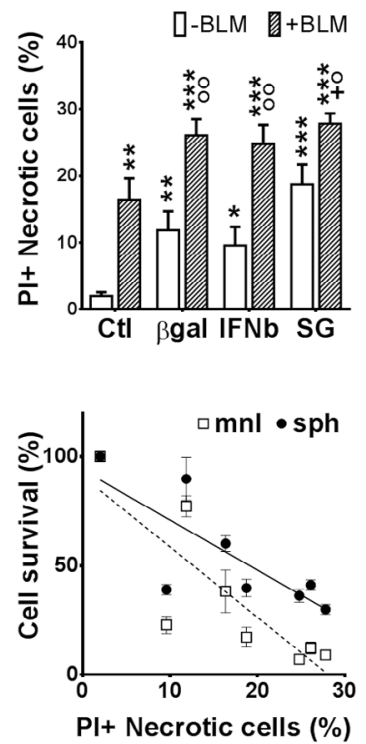

\begin{tabular}{|c|c|c|c|c|c|c|c|c|}
\hline \multirow{2}{*}{ PI+ } & \multicolumn{2}{|c|}{$D c$} & \multicolumn{2}{|c|}{$R n$} & \multicolumn{2}{|c|}{ Bsk } & \multicolumn{2}{|c|}{$R k$} \\
\hline & $\mathbf{R}^{2}$ & p $<$ & $\mathbf{R}^{2}$ & p $<$ & $\mathbf{R}^{2}$ & p< & $\mathbf{R}^{2}$ & p $<$ \\
\hline mnl & 0.858 & 0.001 & 0.513 & 0.05 & 0.919 & 0.001 & 0.703 & 0.01 \\
\hline sph & 0.636 & 0.05 & 0.533 & 0.05 & 0.681 & 0.05 & 0.610 & 0.05 \\
\hline
\end{tabular}

Figure 5: Effects of IFN $\beta$ gene and SG (HSVtk/GCV) lipofection in the absence or presence of BLM on necrotic cell death of melanoma cells. (a) The fraction of necrotic propidium iodide (PI) stained cells was determined by flow cytometry as described in Materials and methods. The results represent means \pm s.e.m. of $\mathrm{n}>3$ independent experiments. ${ }^{*}$ vs the respective $\beta$-galactosidase gene ( $\beta$ gal); O BLM vs their respective value without BLM; + BLM/genes combined treatments vs their respective ctl+BLM; One symbol: $\mathrm{p}$ $<0.05$, two symbols: $\mathrm{p}<0.01$, three symbols: $\mathrm{p}<0.001$. (b) Correlations between necrotic propiduim iodide (PI) stained cells and cells survival to all treatments in $\mathrm{mnl}(\square)$ or $\operatorname{sph}(\bullet)$ were determined by Pearson test with GraphPad Prism program. 
Dc

Bsk

Rk

a)
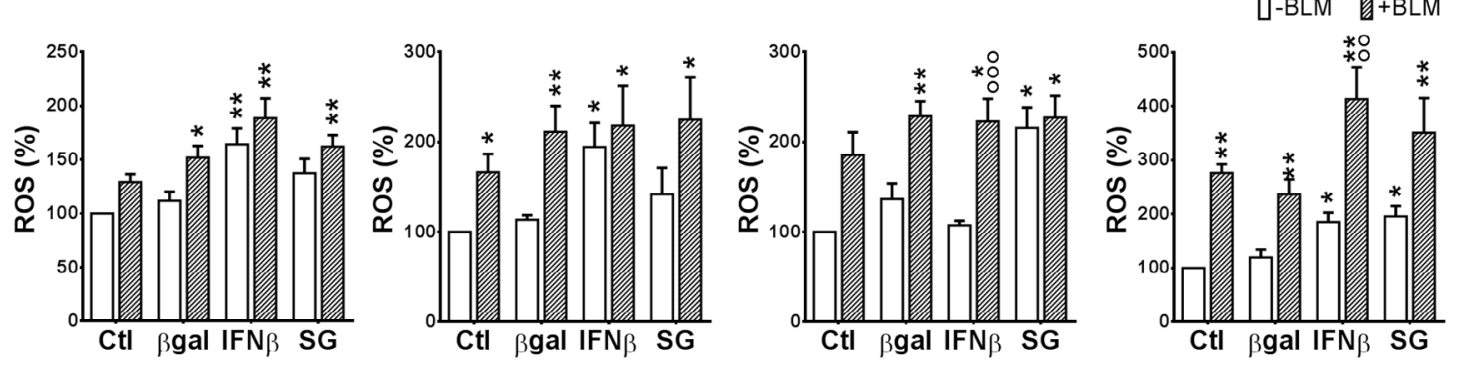

b)
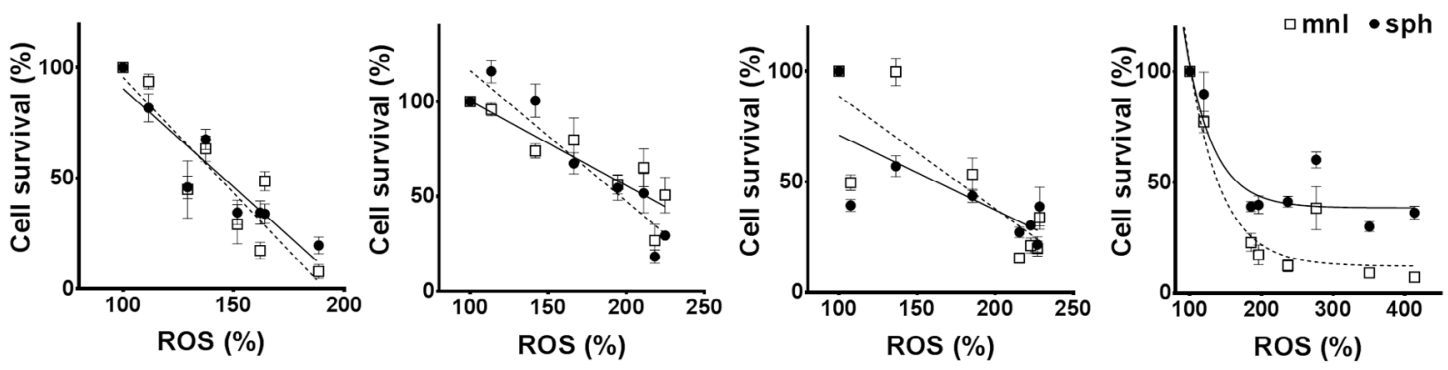

C)
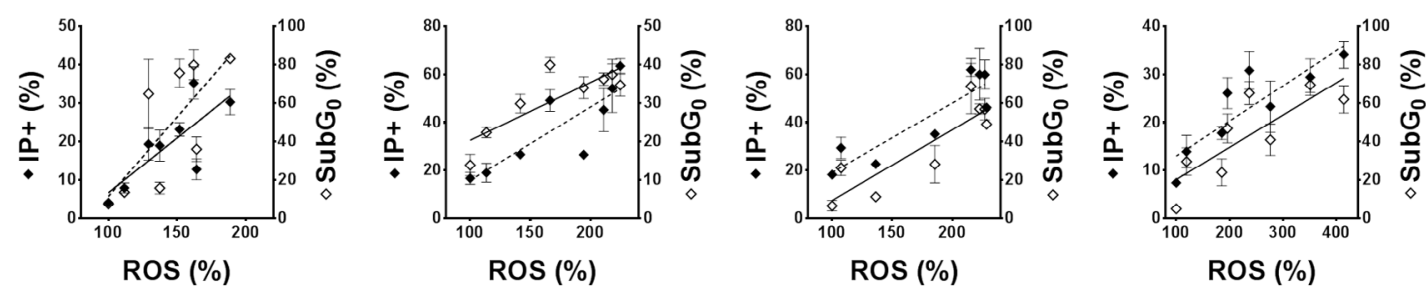

\begin{tabular}{|c|c|c|c|c|c|c|c|c|}
\hline \multirow{2}{*}{ ROS } & \multicolumn{2}{|c|}{$D c$} & \multicolumn{2}{|c|}{$R n$} & \multicolumn{2}{|c|}{ Bsk } & \multicolumn{2}{|c|}{$R k$} \\
\hline & $\mathbf{R}^{2}$ & $\mathbf{p}<$ & $\mathbf{R}^{2}$ & $p<$ & $\mathbf{R}^{2}$ & $p<$ & $\mathbf{R}^{2}$ & $p<$ \\
\hline$\square \mathbf{m n l}$ & 0.831 & 0.01 & 0.799 & 0.01 & 0.673 & 0.05 & 0.839 (exp) & 0.05 \\
\hline - sph & 0.870 & 0.001 & 0.892 & 0.001 & 0.563 & 0.05 & 0.763 (exp) & 0.05 \\
\hline$\bullet \mathrm{IP}+$ & 0.615 & 0.05 & 0.693 & 0.05 & 0.771 & 0.01 & 0.655 & 0.05 \\
\hline$\diamond \mathbf{S u b G}_{0}$ & 0.562 & 0.05 & 0.713 & 0.01 & 0.807 & 0.001 & 0.753 & 0.01 \\
\hline
\end{tabular}

Figure 6: Effects of SG (HSVtk/GCV) and IFN $\beta$ lipofection in the absence or presence of BLM on intracellular reactive oxygen species (ROS) production by melanoma cells. Intracellular ROS levels were measured by means of H2DCF-DA probe as described in Materials and methods. (a) The results represent means \pm s.e.m. of $\mathrm{n} \geq 6$ (Bsk and $D c$ ), and $\mathrm{n} \geq 3$ (Rn and $R k$ ) independent experiments. * vs their respective $\beta$ gal; o BLM vs their respective value without BLM; + BLM/genes combined treatments vs their respective $\beta$ gal $+B L M$. One symbol: $\mathrm{p}<0.05$, two symbols: $\mathrm{p}<0.01$, three symbols: $\mathrm{p}<0.001$. Correlations between the fraction of cells with high levels of intracellular ROS and (b) cells survival to all treatments in mnl ( $\square$ ) or sph (•) or (c) SubG0- apoptotic cells ( $\diamond)$ and PI+ necrotic cells death $(\diamond)$ were determined by Pearson test with GraphPad Prism program. 
Despite the great colony-forming capacity (CFC) of $R n$ untreated cells (Table 1), surviving cells to both SG and BLM (alone or combined treatments) exhibited a significantly decreased CFC.

It is worth to note that the clonogenic capacity of $D c, B s k$ and $R k$ surviving cells almost disappeared after treatment with BLM alone or combined with genes (Fig. $8 a)$.

Fig. $8 \mathrm{~b}$ images represent examples of the clonogenic capacity of the surviving cells to treatments described in the bars plots. $D c, B s k$ and $R k$ cell lines formed growing colonies that were visible in plain sight 10-12 days $(D c$ and $B s k)$ or about 20 days $(R k)$ after seeding. $R n$ colonies were not able to reach the same size of the rest at any time, as they spontaneously became dense spherical colonies that easily detached and persisted at the supernatant of the well plate.

On the other hand, there was a direct correlation between the fraction of surviving cells after any treatment and their CFC in $D c, B s k$ and $R k$ cell lines (Fig. 8c). The higher CFC of Rn cells did not correlate with the extent of the cytotoxic responses.

\section{DISCUSSION}

Tumors are formed from distinct cell populations. This heterogeneity of tumor structure leads to the occurrence of sensitivity and resistance to applied treatment. One of the critical issues in designing efficient therapies is to understand the composition of heterogeneous melanoma tumors to target treatment resistant cell subpopulations. Here, we established and characterized two feline $(D c$ and $R n)$ and two canine (Bsk and $R k$ ) melanoma cell lines from veterinary patients. These cell lines, arose from highly proliferative $(R n>B s k>D c>R k)$ and highly invasive $(R n>B s k>D c>R k)$ advanced tumors. Although the four patients presented stage III disease (tumor $>4 \mathrm{~cm}$ and/or positive nodes), as defined by WHO staging system, feline in vivo tumors $(D c, R n)$ displayed stable disease (reduction or increase
Dc

a)

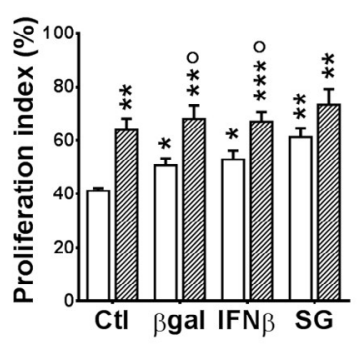

b)

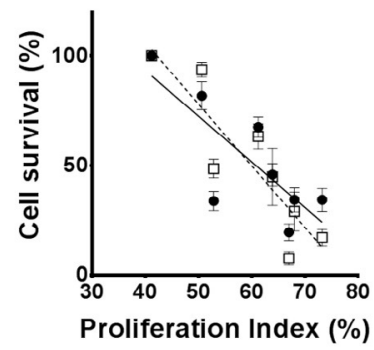

Rn
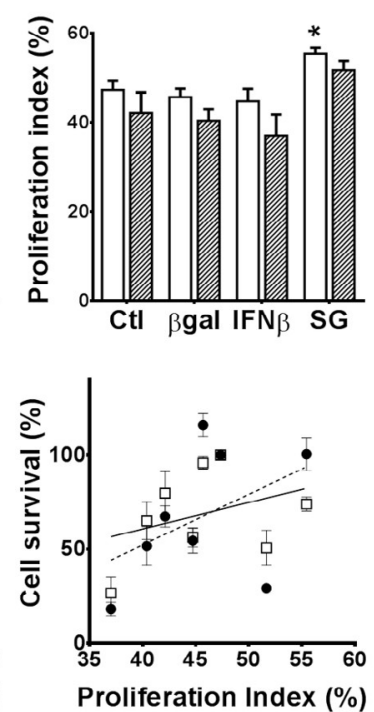

Bsk
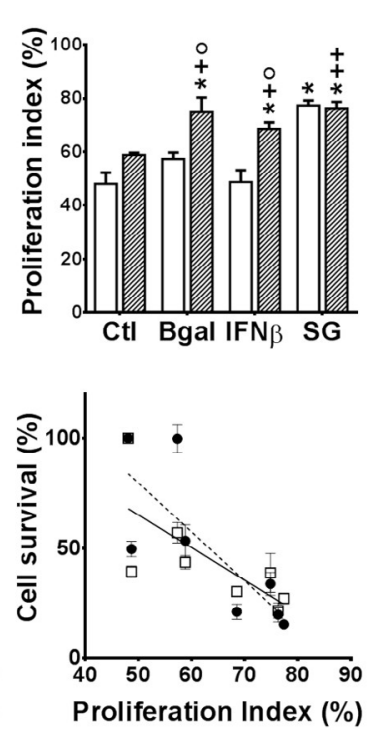

Rk
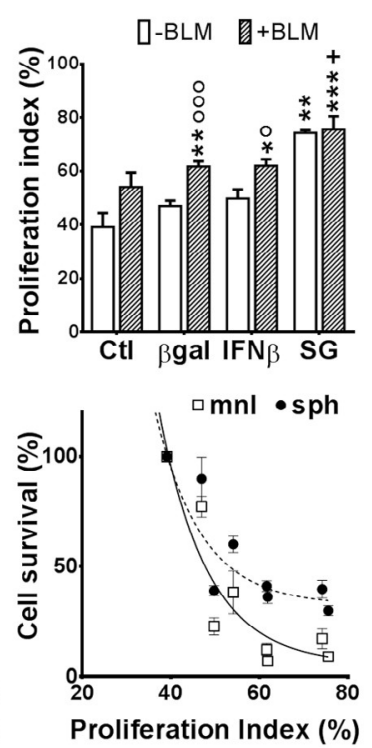

\begin{tabular}{|c|c|c|c|c|c|c|c|c|}
\hline \multirow{2}{*}{ PIx } & \multicolumn{2}{|c|}{$D c$} & \multicolumn{2}{|c|}{$R n$} & \multicolumn{2}{|c|}{ Bsk } & \multicolumn{2}{|c|}{$R k$} \\
\hline & $\mathbf{R}^{2}$ & $p<$ & $\mathbf{R}^{2}$ & $p<$ & $\mathbf{R}^{2}$ & $p<$ & $\mathbf{R}^{2}$ & $p<$ \\
\hline mnl & 0.796 & 0.01 & 0.401 & ns & 0.620 & 0.05 & 0.755 (exp) & 0.05 \\
\hline sph & 0.630 & 0.05 & 0.260 & ns & 0.522 & 0.05 & 0.711 (exp) & 0.05 \\
\hline
\end{tabular}

Figure 7: Effects of SG (HSVtk/GCV) and IFN $\beta$ lipofection in the absence or presence of BLM on the proliferation index (PIx) of melanoma cells. (a) Cells growing for 3 days as monolayers were suspended, treated and subjected to flow cytometry analysis as described in Materials and methods. Proliferation index (PIx) was determined by evaluating the percentage of cells in the S, $\mathrm{G}_{2} / \mathrm{M}$ and hyperdiploid phases. The results represent means \pm s.e.m. of $\mathrm{n} \geq 3$ independent experiments. * vs their respective ctl; o BLM vs their respective value without BLM; + BLM/genes combined treatments vs their respective ctl+BLM. (b) Correlations between PIx and survival cells to all treatments in $\mathrm{mnl}(\square)$ or sph $(\bullet)$ cells were determined by Pearson test with GraphPad Prism program. One symbol: $\mathrm{p}<0.05$, two symbols: $\mathrm{p}<0.01$, three symbols: $\mathrm{p}<0.001$. 
in tumor size $<50 \%$, data not shown), while canine ones $(B s k, R k)$ exhibited partial response (reduction of tumor size $>50 \%$ ) to $\mathrm{SG}$ treatment [5]. This behavior was reflected by their derived melanoma cell lines confirming the behavioral similarity between in vivo tumors and their in vitro models (Fig. 3 ).

Even though it was reported that the aggressiveness of human melanoma is promoted by aneuploidy-driven gene expression deregulation [23], ploidy analysis of the four cell lines tested in this work evidenced that they are euploid ( $2 n$, data not shown). On the other hand in a veterinary setting, survival times in dogs and cats with melanocytic tumors, was not correlated with modifications of DNA content or changes in nuclear morphometry of tumor cells [24]. Therefore the basis for the correlations between in vivo and in vitro tumor cells behavior should be located elsewhere.
Feline cell lines $(D c, R n)$, were more sensitive to IFN $\beta$ gene in both spatial configurations. BLM improved the antitumor effects of both genes, suggesting a useful interaction between them involving powerful cell death mediators. Reactive oxygen species (ROS), triggered by treatments, would be among the main molecules involved in the process [7]. These data, together with the high number of cells with DNA fragmentation and plasma membrane disruption, strongly emphasize the role of ROS as mediators of cell death mostly through apoptotic and necrotic events (Figs. 3-6). Probably BLM, that also increases pro-oxidant species, can complement the antitumor efficacy of the SG and IFN $\beta$ gene and clearly causes potentiated effects.

According to the invasive behavior of their respective tumors, the four cell lines were positive for the mesenchymal marker vimentin (Fig. 2). These
Dc

a)

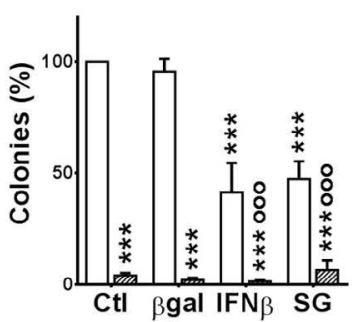

b)

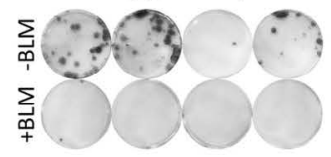

C)

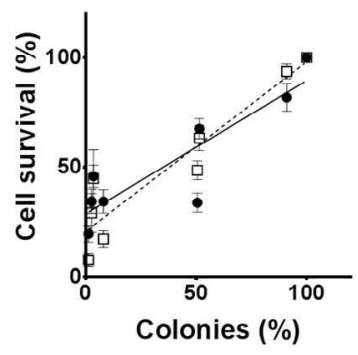

$\mathrm{Rn}$
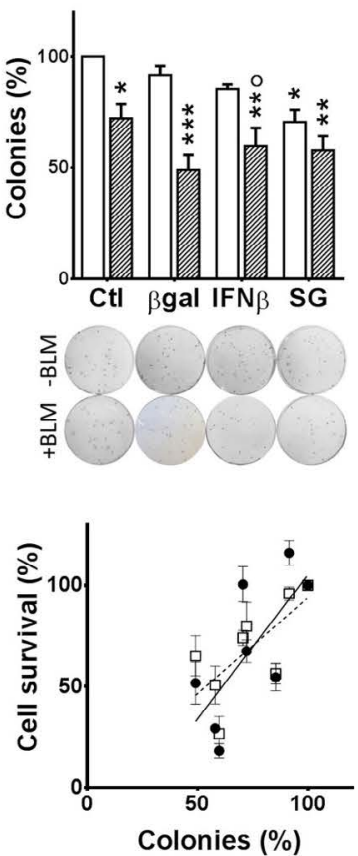

Bsk
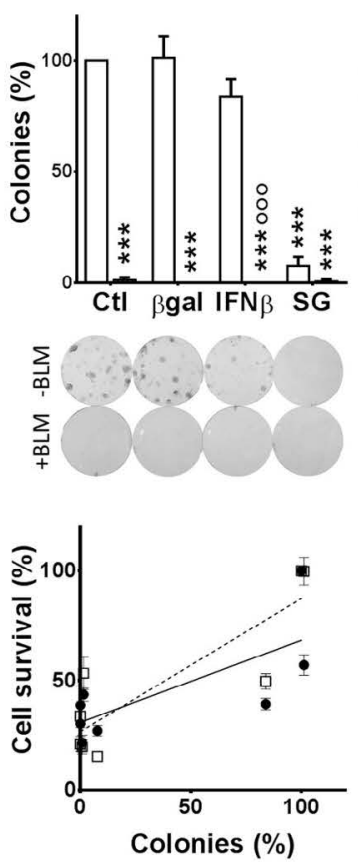

Rk
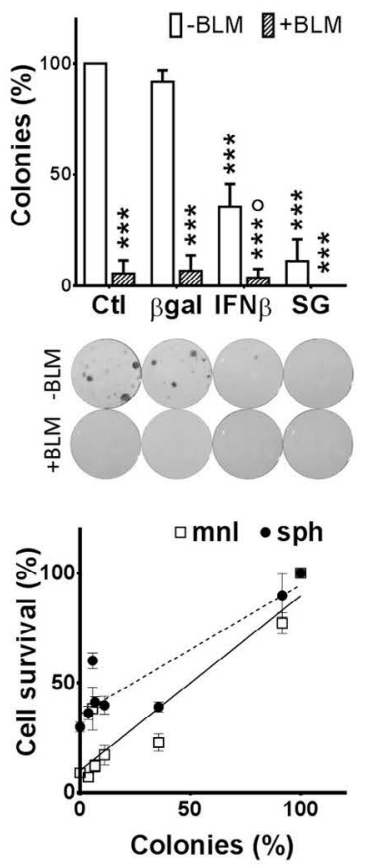

\begin{tabular}{|c|c|c|c|c|c|c|c|c|}
\hline \multirow{2}{*}{ Colonies } & \multicolumn{2}{|c|}{ Dc } & \multicolumn{2}{c|}{ Rn } & \multicolumn{2}{c|}{ Bsk } & \multicolumn{2}{c|}{ Rk } \\
\cline { 2 - 9 } & $\mathbf{R}^{\mathbf{2}}$ & $\mathbf{p}<$ & $\mathbf{R}^{\mathbf{2}}$ & $\mathbf{p}<$ & $\mathbf{R}^{2}$ & $\mathbf{p}<$ & $\mathbf{R}^{2}$ & $\mathbf{p}<$ \\
\hline mnl & 0.882 & 0.001 & 0.478 & ns & 0.739 & 0.01 & 0.882 & 0.001 \\
\hline sph & 0.787 & 0.01 & 0.508 & 0.05 & 0.534 & 0.05 & 0.831 & 0.01 \\
\hline
\end{tabular}

Figure 8: Clonogenic forming capacity of the surviving melanoma cells to SG (HSVtk/GCV) and IFN $\beta$ lipofection in the absence or presence of BLM relative to the number of seeding cells, as described in Materials and methods. (a) The results represent means \pm s.e.m. of $n \geq 3$ independent experiments. * vs their respective $\beta$ gal; o BLM vs their respective value without BLM; + BLM/genes combined treatments vs their respective $\beta$ gal+BLM. One symbol: $p<0.05$, two symbols: $p<0.01$, three symbols: $p<0.001$. (b) Images of a representative experiment. c) Correlations between surviving cells in mnl ( $\square$ ) or sph $(\bullet)$ to all treatments and its clonogenic forming capacity as determined by Pearson test with GraphPad Prism program. 
data suggest that, at the time of tumor resection, a vast subgroup of tumor cells of the total population, had already suffered the epithelial to mesenchymal transition (EMT), increasing their metastatic potential. However, to colonize the metastatic site, cells may reverse in part the EMT by re-expressing basal-like phenotype-associated proteins as cytokeratin (CK) [25]. These vimentin-positive cells also co-expressed $\mathrm{CK}$, confirming their invasive and metastatic behavior [21].

As suggested by Ki67, Melan A and gp100 melanoma antigen expression (Fig. 2), the four cell lines exhibited a proliferative behavior [19]. $B s k, D c$ and $R k$ lines responded to our single and combined treatments by enhancing the fraction of cells actively proliferating (with high PIx, Fig. 7) and with elevated levels of intracellular ROS (Fig. 6). It was stated that cells with high intracellular ROS levels (Fig. 6) are actively proliferating and more sensitive to therapy and differentiation [14]. Besides, higher ROS state induces proliferation and differentiation of tumor initiating cells (TICs) [14-16]. Conversely, low ROS phenotype is a common property of TICs, required for the maintenance of their self-renewal capacity, quiescent state, high tumorigenicity and therapy resistance [14-16].

It is remarkable that $R n$ cell line, that exhibited the lowest levels of ROS, was also enriched with a high proportion of cells with both, small size and high complexity (Table 1). All these parameters have been associated to TICs [14-18]. This cell line, sensitive to single and combined treatments (Fig. 3-5), only displayed a further increase in the proportion of cells with high basal proliferation index (PIx) in response to SG treatment (Fig. 7). These data indicate that even within highly proliferative melanoma cells, a subpopulation resides in a slow-cycling state. These slow-cycling cells, characteristics of melanoma TICs, are essential for continuous tumor growth [25-29]. According to the massive and highly invasive $\mathrm{Rn}$ tumor, long term repopulation by cell re-growth prevail over an early fast destruction by treatments of Rn melanoma cells both in vivo and in vitro (Fig. 3). The high Ki67 staining (Fig. 2), the spheroids multicellular resistance to SG (Fig. 3), the significant increase of apoptotic and necrotic death in response to treatments (Fig. 4, 5) and the highest clonogenic forming capacity (Fig. 8) of Rn surviving cells support this hypothesis. Clonogenic survival studies are useful for to evaluate long-term outcomes of treatments that often differ from short-term cytotoxic effects. When surviving Rn cells (derived from a highly aggressive and metastatic advanced tumor) were seeded in vitro at low density, generated 2-, 2- and 4-fold more colonies in soft agar and 3-, 3- and 7-fold more adherent colonies than the other three cell lines (Table 1 and Fig. 8). In addition, Rn cells showed only a small decrease of CFC of surviving cells to SG and BLM (alone or combined with genes) (Fig. 8).
All these data suggest that tumor initiation was not necessarily restricted to a minor population of $R n$ melanoma cells. This cell line may be enriched in both, treatments-sensitive cells and TICs. Thus, treatments only affect a small fraction of $R n$ TICs, by promoting selfrenewal or proliferation. Conversely, the higher fraction of this particular set remained quiescent, and then, protected from a harsh environment that induce its exhaustion [2529]. Possibly, in the other three cell lines the constant cycling imposed by BLM and the sustained expression of IFN $\beta$ and SG (Fig. 6), leads to TICs exhaustion [26, 27]. This was in fact observed in Fig. 8, where the CFC of surviving cells almost disappeared after treatment with BLM alone or combined with genes. The high correlation between the fraction of $D c, B s k$ and $R k$ cells surviving to treatments with their CFC (Fig. 8) suggested that, our chemo-gene treatments, reduced the melanoma TICs compartment in the three lines by promoting long-term TICs self-renewal, repopulating activity and differentiation.

In our spontaneous canine melanoma clinical trials [5], repeated in vivo intra tumor administrations of lipidcomplexed SG plus GCV yielded $62 \%$ of in vivo objective responses with $30 \%$ complete responses. Since TICs are responsible of tumor recurrence and metastatic disease [28], the high proportion of tumor complete responses and metastasis-free patients suggests that our SG therapy was able to eliminate TICs in vivo [5]. In addition, our surgery adjuvant veterinary clinical trials combination of a plasmid DNA vaccine with local SG [5] and SG plus cIFN $\beta$ [6] delayed or prevented post-surgical recurrence and distant metastasis while significantly improved disease-free and overall survival of our canine patients. Other combination of BLM (as electrochemotherapy) with a cytokine gene (IL-12) electrotransfer was successfully tested in veterinary patients [30].

The effective clinical outcome of our veterinary clinical trials suggest that in vivo continuous and sustained local expression of SG and cIFN $\beta$ gene, reduce TICs [57], and that such behavior was reflected by their derived melanoma cell lines [11]. In addition, the results presented here suggest that BLM improves the antitumor effects of both genes in both spatial configurations, and produces a moderate $(R n)$ or dramatic reduction $(D c, B s k, R k)$ in the CFC of surviving cells in the four melanoma cell lines (Fig. 8a). The previously published clinical data [5, 6] together with the in vitro data presented here, suggest that the combination of BLM plus gene treatments could eradicate TICs in vivo and strongly supporting the clinic potential of this strategy. 


\section{MATERIALS AND METHODS}

\section{Veterinary patients}

Cats and dogs with a confirmed histopathological diagnostic of melanoma were recruited for a study as it was reported $[5,6]$. Their owners were notified about the experimental nature of the treatment, and all of them granted written informed consent for treatment $[5,6]$. These tumors were staged by a veterinary oncologist according to the WHO staging system of stage III (tumor $>4 \mathrm{~cm}$ and/or positive lymph nodes). These spontaneous melanoma veterinary patients received twice a week during 5 weeks, intra- and peri- tumor injection at multiple sites of lipid-complexed plasmid DNA encoding HSVtk (1 to $4 \mathrm{mg}$ DNA co-delivered with 5-20 mg GCV according the tumor size).

\section{Establishment of cell cultures from feline and canine melanoma tumors}

Primary cell lines derived from surgically excised feline oral $(D c)$ and abdominal mucosal melanoma $(R n)$ and canine oral (Bsk and $R k$ ) melanomas were obtained by mechanical disruption of tumor fragments in culture medium [7, 9]. Periodically tested for mycoplasma absence, cells were cultured as monolayers and multicellular spheroids as described [7,9].

For doubling time estimation using GraphPad Prism 6 software (GraphPad Software Inc.), cells were trypsinized and $5 \times 104$ cells were plated in duplicate in 6-well plates and cultured in normal conditions. After trypan blue staining, cells were daily counted in a Neubauer chamber.

\section{Immunocytochemistry}

Cells attached onto a glass slide were cultured for $48 \mathrm{~h}$ in the above described conditions. Cells were then washed, fixed with ethanol, dried, re-hydrated and incubated separately with the following specific antihuman monoclonal antibodies as described by the manufacturers: (i) from BioGenex: melan A (clone A103), S-100A9 (clone 15E2E2), GP100 (clone HMB45); (ii) from Dako: cytokeratin (clones AE1/AE3), vimentin, CD68 and Ki67. After washing, cells were incubated $2 \mathrm{~h}$ at room temperature, with Multi-Link immunoglobulins (BioGenex) followed by streptavidin/peroxidase conjugate and developed with 3,3'-diaminobenzidine [11].

\section{Plasmids and transfection efficiency}

Plasmids psCMVßgal $(6.8 \mathrm{~Kb})$ [11], psCMVtk $(4.5 \mathrm{~Kb})$ [11], psCMVcIFN $\beta \quad(3.9 \mathrm{~Kb})$ [7] and psCMVfIFN $\beta(3.9 \mathrm{~Kb})$ carry respectively Escherichia coli $\beta$-galactosidase gene $(3.5 \mathrm{~Kb})$, herpes simplex thymidine kinase $(1.2 \mathrm{~Kb})$ and canine or feline IFN $\beta$ $(0.6 \mathrm{~Kb})$ in the polylinker site of psCMV $(3.3 \mathrm{~Kb})$, downstream of the CMV promoter and upstream of poly A sequences. The plasmids (bearing the kanamycin resistance gene for selection in Escherichia coli) were amplified, chromatographically purified and quality assessed as described [11]. Plasmid DNA for injection was resuspended to a final concentration of $2.0 \mathrm{mg} / \mathrm{ml}$ in sterile PBS.

\section{Liposome preparation and in vitro lipofection}

DC-Chol $\quad\left(3 \beta\left[\mathrm{N}-\left(\mathrm{N}^{\prime}, \mathrm{N}^{\prime}\right.\right.\right.$-dimethylaminoethane)carbamoyl cholesterol) was kindly supplied by BioSidus. DMRIE (1,2-dimyristyl oxypropyl-3-dimethylhydroxyethylammonium bromide) was kindly synthesized and provided by Dr. Eduardo M. Rustoy. DOPE (1,2-dioleoyl-sn-glycero-3-phosphatidyl ethanolamine) was purchased from Sigma. Liposomes were prepared at lipid/co-lipid molar ratios of 3:2 (DCChol:DOPE) or 1:1 (DMRIE:DOPE) by sonication as described [11]. Optimal lipid mixtures were determined for every cell line.

Cells, seeded onto 12-well plates at a density of $3-5 \times 10^{4}$ cells $/ \mathrm{cm}^{2}$ were allowed to adhere overnight. Monolayers were exposed to lipoplexes $(0.5 \mu \mathrm{g}$ plasmid $\mathrm{DNA} / \mathrm{cm}^{2}$ and $1 \mu \mathrm{l}$ liposome $/ \mathrm{cm}^{2}$ ) from 3 to $5 \mathrm{~h}$ in a serumfree medium. Then the lipofection medium was replaced with fresh complete medium. The feline and canine cells were lipofected with psCMV-fIFN $\beta$ and psCMV-cIFN $\beta$ respectively.

Lipofection rates were checked $24 \mathrm{~h}$ after lipofection by $\beta$-galactosidase staining with 5-bromo-4chloro-3-indolyl $\beta$-D-galactopyranoside (X-GAL, Sigma) and further counting with an inverted phase contrast microscope [11].

\section{Sensitivity to bleomycin, suicide gene and IFN $\beta$ gene assays}

Twenty-four hours after lipofection, with suicide gene (SG, HSV $t k / \mathrm{GCV}$ ), feline/canine interferon- $\beta$ (fIFN $\beta$, cIFN $\beta$ ) or $\beta$ gal alone or co-delivered with 3 $\mu \mathrm{g} / \mathrm{ml}$ bleomycin (Gador), cells were seeded on regular plates as monolayer $\left(3.5-7.0 \times 10^{4}\right.$ cells $\left./ \mathrm{ml}\right)$ or on top of $1.5 \%$ solidified agar to form spheroids $\left(1.0 \times 10^{5}\right.$ cells/ $\mathrm{ml}$ ) and incubated with medium containing $5 \mu \mathrm{g} / \mathrm{ml}$ ganciclovir (Richet). After 5 days in monolayers or 12 days in spheroids, cell viability was quantified with acid phosphatase assay (APH) as described [7, 9]. 


\section{Flow cytometry cell cycle analysis and quantification of DNA fragmentation}

Three days after lipofection, with SG, IFN $\beta$, or $\beta$ gal alone or co-delivered with BLM, cells were trypsinized, fixed in $70 \%(\mathrm{v} / \mathrm{v})$ ethanol at $-20^{\circ} \mathrm{C}$ for $1 \mathrm{~h}$, treated with RNase, stained with $10 \mu \mathrm{g} / \mathrm{ml}$ propidium iodide (PI, Sigma) for $30 \mathrm{~min}$, and subjected to single-channel flow cytometry on a Becton Dickinson FACScan (Franklin Lakes), with analysis of data performed using the Cylchred software (Cardiff University). Cells displaying a hypodipoid content of DNA indicative of DNA fragmentation were scored as apoptotic-necrotic.

\section{Quantification of necrotic cells}

Three days after lipofection, with SG, IFN $\beta$, or $\beta$ gal alone or co-delivered with BLM, cells were harvested, freshly stained (without fixation) with PI solution $(5 \mu \mathrm{g} /$ $\mathrm{ml}$ ) for $5 \mathrm{~min}$, and then analyzed by flow cytometry as described above. PI enters the cells only if there is a loss of membrane integrity. Then, PI positive cells were scored as necrotic.

\section{Measurement of cellular reactive oxygen species (ROS) production}

Three days after lipofection with SG, IFN $\beta$, or $\beta$ gal alone or co-delivered with BLM, cells were detached, washed with PBS and incubated with $0.5 \mu \mathrm{M}$ H2DCFDA (Invitrogen) in PBS [7]. After $20 \mathrm{~min}$, normal culture conditions were re-established and the cellular fluorescence intensity was analyzed by flow cytometry. The final data were analyzed using the Flowing software (2.5.1, Finland) and the medium intensity of fluorescence was calculated (Geometric Mean: Gm).

\section{Determination of size and granularity or internal complexity of melanoma cells}

Cell size and complexity of control untreated cells were analyzed by physical parameters of flow cytometry. Forward scatter intensity mainly correlates with cell area or size, and side scatter is a measure of the cell refractive index that depends on the cell granularity or internal complexity.

\section{Colony formation assay}

Surviving cells after 3 days of BLM-gene treatments were trypsinized up to single cells. Monodispersed cells were seeded at low density and incubated at $37^{\circ} \mathrm{C}$ with complete medium until colonies were visible. To generate a similar number of colonies, it was necessary to seed different number of surviving cells: $500(R n), 1500(D c$, $B s k)$ and $2500(R k)$ cells in a 6-well plate. Medium was changed once a week. After 7-10 days of culture, plates were washed, fixed with ethanol:acetic acid $(3: 1, \mathrm{v} / \mathrm{v})$, and stained with crystal violet. The number of colonies was counted under an inverted microscope. The clonogenic capacity was defined as the percentage of seeded cells able to grow as colonies of more than 10 cells.

\section{Cloning efficiency in soft agar}

Dispersed cells were resuspended in $0.25 \%$ agar in culture medium at $1 \times 10^{4}$ cells $/ \mathrm{ml}$ and layered on top of $0.5 \%$ agar in culture medium. Three weeks after initiating cultures, colonies were counted.

\section{Melanosphere formation assay}

Surviving cells after 3 days of BLM-gene treatments were trypsinized up to single cells and plated onto 12-well low attachment suspension culture plates (Greiner BioOne) at a density of $2000-2500$ viable cells $/ \mathrm{ml}$. Cells were grown in $1 \mathrm{ml}$ serum-free media, supplemented with B27 (Gemini Bioproducts), and $20 \mathrm{ng} / \mathrm{ml}$ EGF. Melanospheres were counted after 6-8 days in culture. The melanosphere forming capacity was defined as the percentage of cells able of clonal proliferation as melanospheres with more than 8 cells.

\section{Statistics}

Results were expressed as mean \pm standard error of the mean (s.e.m.) (n: number of experiments corresponding to independent assays). Differences between groups were analyzed using unpaired Student's t-test (if two groups), one-way ANOVA followed by Tukey's test (if more than two groups) or two-way ANOVA followed by Bonferroni test (if two nominal variables). Correlations were determined by Pearson test with GraphPad Prism program (GraphPad Software Inc.).

\section{ACKNOWLEDGMENTS AND FUNDING}

We thank María D. Riveros and Graciela B. Zenobi for technical advice and assistance, Lina A. Marino for immunocytochemistry analysis. This study was partially supported by grants from ANPCYT/FONCYT (PICT20121738) and CONICET (PIP 112201101 00627). MSV, GCG and LMEF are investigators, and LA and CF fellows of the Consejo Nacional de Investigaciones Científicas y Técnicas (CONICET, Argentina). 


\section{CONFLICTS OF INTEREST}

The authors declare no conflicts of interest.

\section{REFERENCES}

1. Finocchiaro LME, Glikin GC. Recent clinical trials of cancer immunogene therapy in companion animals. World J Exp Med. 2017; 7: 42-48. doi: 10.5493/wjem.v7.i2.42

2. Glikin GC, Finocchiaro LM. Clinical trials of immunogene therapy for spontaneous tumors in companion animals. ScientificWorldJournal. 2014; 2014: 718520. doi: $10.1155 / 2014 / 718520$

3. Chamel G, Abadie J, Albaric O, Labrut S, Ponce F, Ibisch C. Non-ocular melanomas in cats: a retrospective study of 30 cases. J Feline Med Surg. 2017; 19: 351-357. doi: $10.1177 / 1098612$ X15625355

4. Ramos-Vara JA, Beissenherz ME, Miller MA, Johnson GC, Pace LW, Fard A, Kottler SJ. Retrospective study of 338 canine oral melanomas with clinical, histologic, and immunohistochemical review of 129 cases. Vet Pathol. 2000; 37: 597-608. doi: 10.1354/vp.37-6-597

5. Finocchiaro LM, Glikin GC. Cytokine-enhanced vaccine and suicide gene therapy as surgery adjuvant treatments for spontaneous canine melanoma: 9 years of followup. Cancer Gene Ther. 2012; 19: 852-61. doi: 10.1038/ cgt.2012.72

6. Finocchiaro LM, Fondello C, Gil-Cardeza ML, Rossi ÚA, Villaverde MS, Riveros MD, Glikin GC. CytokineEnhanced Vaccine and Interferon- $\beta$ plus Suicide Gene Therapy as Surgery Adjuvant Treatments for Spontaneous Canine Melanoma. Hum Gene Ther. 2015; 26: 367-76. doi: 10.1089/hum.2014.130

7. Rossi ÚA, Gil-Cardeza ML, Villaverde MS, Finocchiaro LM, Glikin GC. Interferon- $\beta$ gene transfer induces a strong cytotoxic bystander effect on melanoma cells. Biomed Pharmacother. 2015; 72: 44-51. doi: 10.1016/j. biopha.2015.04.002

8. Kirkwood JM, Ibrahim JG, Sondak VK, Richards J, Flaherty LE, Ernstoff MS, Smith TJ, Rao U, Steele M, Blum RH. High- and low-dose interferon alfa-2b in highrisk melanoma: first analysis of intergroup trial E1690/ S9111/C9190. J Clin Oncol. 2000; 18: 2444-58. doi: 10.1200/JCO.2000.18.12.2444

9. Gil-Cardeza ML, Rossi ÚA, Villaverde MS, Glikin GC, Finocchiaro LM. Cationic lipid:DNA complexes allow bleomycin uptake by melanoma cells. Biomed Pharmacother. 2013; 67: 269-75. doi: 10.1016/j. biopha.2013.01.002

10. Villaverde MS, Gil-Cardeza ML, Glikin GC, Finocchiaro LM. Interferon- $\beta$ lipofection I. Increased efficacy of chemotherapeutic drugs on human tumor cells derived monolayers and spheroids. Cancer Gene Ther. 2012; 19: 508-16. doi: 10.1038/cgt.2012.27
11. Gil-Cardeza ML, Villaverde MS, Fiszman GL, Altamirano NA, Cwirenbaum RA, Glikin GC, Finocchiaro LM. Suicide gene therapy on spontaneous canine melanoma: correlations between in vivo tumors and their derived multicell spheroids in vitro. Gene Ther. 2010; 17: 26-36. doi: $10.1038 /$ gt.2009.107

12. Quintana E, Shackleton M, Foster HR, Fullen DR, Sabel MS, Johnson TM, Morrison SJ. Phenotypic heterogeneity among tumorigenic melanoma cells from patients that is reversible and not hierarchically organized. Cancer Cell. 2010; 18: 510-23. doi: 10.1016/j.ccr.2010.10.012

13. Somasundaram R, Villanueva J, Herlyn M. Intratumoral heterogeneity as a therapy resistance mechanism: role of melanoma subpopulations. Adv Pharmacol.2012; 65: 33559. doi: 10.1016/B978-0-12-397927-8.00011-7

14. Chang CW, Chen YS, Chou SH, Han CL, Chen YJ, Yang CC, Huang CY, Lo JF. Distinct subpopulations of head and neck cancer cells with different levels of intracellular reactive oxygen species exhibit diverse stemness, proliferation, and chemosensitivity. Cancer Res. 2014; 74 : 6291-305. doi: 10.1158/0008-5472

15. Shi X, Zhang Y, Zheng J, Pan J. Reactive oxygen species in cancer stem cells. Antioxid Redox Signal. 2012; 16: 121528. doi: 10.1089/ars.2012.4529

16. Yoneyama M, Kawada K, Gotoh Y, Shiba T, Ogita K. Endogenous reactive oxygen species are essential for proliferation of neural stem/progenitor cells. Neurochem Int. 2010; 56: 740-6. doi: 10.1016/j.neuint.2009.11.018

17. Ramirez JM, Bai Q, Péquignot M, Becker F, Kassambara A, Bouin A, Kalatzis V, Dijon-Grinand M, De Vos J. Side scatter intensity is highly heterogeneous in undifferentiated pluripotent stem cells and predicts clonogenic selfrenewal. Stem Cells Dev. 2013; 22: 1851-60. doi: 10.1089/ scd.2012.0658

18. Li Q, Rycaj K, Chen X, Tang DG. Cancer stem cells and cell size: A causal link? Semin Cancer Biol. 2015; 35: 1919. doi: 10.1016/j.semcancer.2015.07.002

19. Zhao WY, Xu J, Wang M, Zhang ZZ, Tu L, Wang CJ, Lin TL, Shen YY, Liu Q, Cao H. Prognostic value of Ki67 index in gastrointestinal stromal tumors. Int J Clin Exp Pathol. 201; 7: 2298-304.

20. Dissanayake SK, Olkhanud PB, O'Connell MP, Carter A, French AD, Camilli TC,Emeche CD, Hewitt KJ, Rosenthal DT, Leotlela PD, Wade MS, Yang SW, Brant L et al. Wnt5A regulates expression of tumor-associated antigens in melanoma via changes in signal transducers and activators of transcription 3 phosphorylation. Cancer Res. 2008; 68: 10205-14. doi: 10.1158/0008-5472.CAN-08-2149

21. Hendrix MJ, Seftor EA, Chu YW, Seftor RE, Nagle RB, McDaniel KM, Leong SP, Yohem KH, Leibovitz AM, Meyskens FL Jr, et al. Coexpression of vimentin and keratins by human melanoma tumor cells: correlation with invasive and metastatic potential. J Natl Cancer Inst. 1992; 84: $165-74$

22. Cheng P, Corzo CA, Luetteke N, Yu B, Nagaraj S, Bui MM, 
Ortiz M, Nacken W, Sorg C, Vogl T, Roth J, Gabrilovich DI. Inhibition of dendritic cell differentiation and accumulation of myeloid-derived suppressor cells in cancer is regulated by S100A9 protein. J Exp Med. 2008; 205: 2235-49. doi: 10.1084/jem.20080132

23. Mathieu V, Pirker C, Schmidt WM, Spiegl-Kreinecker S, Lötsch D, Heffeter P, Hegedus B, Grusch M, Kiss R, Berger W. Aggressiveness of human melanoma xenograft models is promoted by aneuploidy-driven gene expression deregulation. Oncotarget. 2012; 3: 399-413. doi: 10.18632/ oncotarget. 473

24. Roels SL, Van Daele AJ, Van Marck EA, Ducatelle RV. DNA ploidy and nuclear morphometric variables for the evaluation of melanocytic tumors in dogs and cats. Am J Vet Res. 2000; 61: 1074-9. doi: 10.2460/ajvr.2000.61.1074

25. Thiery JP, Acloque H, Huang RY, Nieto MA. Epithelialmesenchymal transitions in development and disease. Cell. 2009; 139: 871-90. doi: 10.1016/j.cell.2009.11.007

26. Roesch A, Fukunaga-Kalabis M, Schmidt EC, Zabierowski SE, Brafford PA, Vultur A, Basu D, Gimotty P, Vogt T, Herlyn M. A temporarily distinct subpopulation of slow-cycling melanoma cells is required for continuous tumor growth. Cell. 2010; 141:583-94. doi: 10.1016/j. cell.2010.04.020

27. Cheung TH, Rando TA. Molecular regulation of stem cell quiescence. Nat Rev Mol Cell Biol. 2013; 14: 329-40. doi: 10.1038/nrm3591

28. Schatton T, Murphy GF, Frank NY, Yamaura K, WaagaGasser AM, Gasser M, Zhan Q, Jordan S, Duncan LM, Weishaupt C, Fuhlbrigge RC, Kupper TS, Sayegh MH wt al. Identification of cells initiating human melanomas. Nature. 2008; 451: 345-9. doi: 10.1038/nature06489

29. Grichnik JM, Burch JA, Schulteis RD, Shan S, Liu J, Darrow TL, Vervaert CE, Seigler HF. Melanoma, a tumor based on a mutant stem cell? J Invest Dermatol. 2006; 126: 142-53. doi: 10.1038/sj.jid.5700017

30. Cemazar M, Ambrozic Avgustin J, Pavlin D, Sersa G, Poli A, Krhac Levacic A, Tesic N, Lampreht Tratar U, Rak M, Tozon N. Efficacy and safety of electrochemotherapy combined with peritumoral IL-12 gene electrotransfer of canine mast cell tumours. Vet Comp Oncol. 2017; 15: 641654. doi: $10.1111 /$ vco. 12208 